\title{
Evaluation of Eruption Pattern and Caries Occurrence among Children Affected with Fluorosis
}

\author{
Shivangi Trivedi ${ }^{1}$, Aparna Trivedi ${ }^{2}$, Naveen R Banda ${ }^{3}$, Nitu Mishra ${ }^{4}$, Garima Singh ${ }^{5}$, Ekta Srivastava ${ }^{6}$, Dinraj Kulkarni ${ }^{7}$
}

\begin{abstract}
Aim: The aim of this study was to evaluate eruption pattern and occurrence of caries in children affected with fluorosis.

Materials and methods: One hundred and fifty subjects (75 each with/without fluorosis) with age group of 7-8 years were selected. Dental fluorosis assessed on the buccal surfaces of the permanent incisors and molars and scored using the Thylstrup and Fejerskov index. The tooth were scored as emerged when at least one cusp of the tooth was visible in the mouth. Caries attack rate in primary and permanent teeth were estimated using DMFS and defs index in fluorosis patient. The findings were subjected to statistical analysis. The data were analyzed using Student " $t$ " test and ANOVA " $F$ "test. Results: There was statistically highly significant difference found in the incidence of occlusal, mesioproximal, and distoproximal caries between fluorotic and nonfluorotic patients $(p<0.001)$. The result of present study showed a nonsignificant association between fluoride exposure parameter and median emergence ages of permanent incisors and molar teeth. On the other hand, caries occurrence shows a significant association with fluorosis.

Conclusion: In this study, a significant positive correlation exists in the prevalence of caries and fluorosis. It is concluded that occlusal and proximal caries are less pronounced in fluorosis patients.

Clinical significance: Dental caries is a public health problem. In this study, we study the fluoride effect since the predominant cariostatic effect of fluoride is beneficial in extensive caries reduction without a concomitant risk of dental fluorosis.

Keywords: Dental caries, Eruption pattern of permanent teeth, Fluorosis.

The Journal of Contemporary Dental Practice (2019): 10.5005/jp-journals-10024-2663
\end{abstract}

\section{INTRODUCTION}

It is believed that children who have been exposed to fluoridecontaining communal water are less prone to dental caries in comparison to those who have always lived in areas where the community water is fluoride free. This fact led to the hypothesis that blood-borne fluoride deposited in enamel during calcification was primarily responsible for caries-inhibitory effect and that the period of fluoride exposure essential to the inhibition of dental caries was that from birth to the age of 8 years.

Acceleration or retardation of permanent teeth eruption is a matter of interest to both anthropologists and those concerned with growth and development.

Since dentistry has widened its horizon towards many specific fields, the rationalization of eruption timings of permanent teeth need to be established for diagnosis, orthodontic treatment planning, and may have legal as well as forensic application. Timing of permanent teeth emergence can be modified by a variety of factors such as carious condition, fluoride, socioeconomic status, systemic diseases, trauma, genetics, nutrition, and craniofacial morphology.

Although there are numerous studies about the effects of fluoride on progress of dental caries, little information is available concerning the possible effects of fluoride on process of tooth eruption.

Various observations have been made indicating an apparent delay in tooth eruption in the individuals living in areas of endemic dental fluorosis; other investigators have failed to confirm these findings. It has also been reported that a high concentration of fluoride substantially reduced the rate of eruption of teeth. ${ }^{1}$

The aim of this study was to evaluate and compare eruption pattern and occurrence of caries among the children affected with fluorosis and without fluorosis.
'Department of Conservative Dentistry and Endodontics, Maharishi Markandeshwar College of Dental Sciences and Research, Ambala, Haryana, India

2Department of Prosthodontics, Crown and Bridge and Implantology, Modern Dental College and Research Centre, Indore, Madhya Pradesh, India

${ }^{3}$ Department of Pedodontics and Preventive Dentistry, Ibn Sina National College for Medical Studies, Jeddah, Kingdom of Saudi Arabia

${ }^{4}$ Department of Oral Pathology and Microbiology, Modern Dental College and Research Centre, Indore, Madhya Pradesh, India

${ }^{5}$ Department of Pedodontics and Preventive Dentistry, Institute of Dental Education and Advance Studies, Gwalior, Madhya Pradesh, India

${ }^{6}$ Department of Pedodontics and Preventive Dentistry, SMBT Dental College and Hospital, Sangamner, Maharashtra, India

${ }^{7}$ Department of Oral and Maxillofacial Pathology, MA Rangoonwala Dental College and Research Center, Pune, Maharashtra, India

Corresponding Author: Nitu Mishra, Department of Oral Pathology and Microbiology, Modern Dental College and Research Centre, Indore, Madhya Pradesh, India, Phone: +91 9406606099, e-mail: dr. nitumishra@gmail.com

How to cite this article: Trivedi S, Trivedi A, Banda NR, et al. Evaluation of Eruption Pattern and Caries Occurrence among Children Affected with Fluorosis. J Contemp Dent Pract 2019;20(10):1217-1222.

Source of support: Nil

Conflict of interest: None

\section{Materials and Methods}

Prior permission was obtained from the school (Saskiya Prathmik Vidyalaya, Nainod, Indore, Madhya Pradesh) authorities for the

o The Author(s). 2019 Open Access This article is distributed under the terms of the Creative Commons Attribution 4.0 International License (https://creativecommons. org/licenses/by-nc/4.0/), which permits unrestricted use, distribution, and non-commercial reproduction in any medium, provided you give appropriate credit to the original author(s) and the source, provide a link to the Creative Commons license, and indicate if changes were made. The Creative Commons Public Domain Dedication waiver (http://creativecommons.org/publicdomain/zero/1.0/) applies to the data made available in this article, unless otherwise stated. 
examination of subjects. A total of 150 children ( 75 with fluorosis and 75 without fluorosis) in the age group of 7-8 years were randomly selected through cluster sampling (i.e., school) using following inclusion and exclusion criteria.

\section{Inclusion Criteria}

- Children with 7-8 years age group

- Subjects who were physically healthy

- Subjects who were mentally healthy

\section{Exclusion Criteria}

- Children below or above 7-8 years of age

- Children with a history of chronic infectious disease, chronic fever, as well as nutritional and endocrine disturbances

- Children with developmental disturbances.

Among group I (75 subjects with fluorosis), 44 were male and 31 were female, while in group II (75 subjects without fluorosis) 40 were male and 35 were female, respectively. The children were informed briefly about the procedure involved. Further an informed consent was taken from parents for all children and proformas were designed. The ages of the children were recorded as age at last birthday and were confirmed from school records.

Mouth mirror and probe with natural light was used for examination. Two examiners were involved in the study. As there is a lack of data on the amount of fluoride (approx. 0.8-1.1 mg/L) in drinking water of communities, the assessment of fluorosis was based on the clinical signs of fluorosis on permanent teeth. It was reported that Saskiya Prathmik Vidyalaya, Nainod area was endemic for fluorosis. Dental fluorosis was assessed on the labial/buccal surfaces of fully erupted upper and lower incisors and first molars and scoring was done using the Thylstrup and Fejerskov index (TFI). A child was assigned fluorosis-positive when fluorosis was recorded on at least 2 of the index teeth.

Index tooth were recorded as "emerged" if atleast one cusp was visible in the mouth. Caries attack rate was estimated on all the erupted teeth using DMFS/defs index with the help of mouth mirror and probe.

The mean number of erupted incisors and molars according to grade of TFI among subjects with fluorosis was calculated by ANOVA " $F$ " test. Mean number of erupted central incisor and molar teeth according to age among subjects without fluorosis calculated by Student " $t$ " test. Comparison of a mean number of erupted incisor and molar teeth according to age among subjects with fluorosis without fluorosis calculated by Student " $t$ " test. The mean number of decayed tooth surface among subjects with or without fluorosis calculated by Student " $t$ " test. The mean number of decayed tooth surface according to grade of TFI among subjects with fluorosis was calculated by ANOVA " $F$ " test and the Pearson's correlation of TFI for fluorosis with mean number of decayed surface on molar and incisor was done.

\section{Results}

In the study, conducted 84 boys and 66 girls participated. Among group I out of 75 subjects, 44 (52.4\%) were male and 31 (47.0\%) were females, while among group II out of 75 subjects, 40 (47.6\%) were male and females were 35 (53.0\%). Figure 1 reveals no significant difference in the distribution of study subjects according to gender and fluorosis $(p=0.511)$.

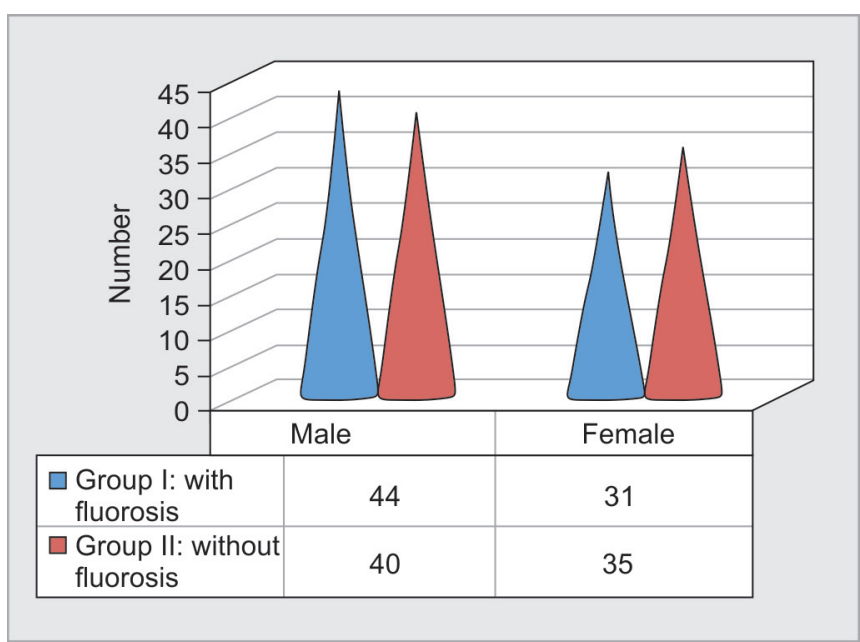

Fig. 1: Demographic distribution of study subjects according to gender and fluorosis

The association between any fluoride exposure parameter and median emergence ages of permanent incisors and molar teeth was minimal and not significant (Fig. 2). It reveals a mean number of erupted incisor and molar teeth according to the grade of TFI among subjects with fluorosis. Among score 1 subjects, the mean numbers of molar and incisor teeth were less, i.e., $3.60 \pm 1.17$ and $4.91 \pm 2.66$. As TFI score is increasing, the mean number of erupting teeth is also increasing. There was no significant difference in the distribution of mean number of incisor and molar teeth according to grade of TFI ( $p=0.492$ and $p=0.170$ ). The difference between emergence patterns of permanent incisors and molars among subjects with and without fluorosis were not statistically significant (Fig. 3). Figure 4 presents data on caries experience among subjects with and without fluorosis. Mean number of decayed surface were comparatively less among group I subjects with fluorosis, it indicates that fluoride reduces the incidence of dental caries. Mostly occlusal, mesioproximal (MP) and distoproximal (DP) surfaces are involved. Lingual surface was almost not involved. Mean occlusal caries was $0.67 \pm 1.02$ and $1.40 \pm 1.52$ among group I and II, respectively. A highly significant difference was found in incidence of occlusal, MP, and DP caries between group I and II $(p<0.001)$.

Figure 5 presents data on caries experience according to grade of TFI among subjects with fluorosis. Among patients with TFI score 1 and 3, decayed tooth surface was comparatively less when compared to a higher TFI score. Among patients with TFI score 1, it was $1.02 \pm 1.43$ and among TFI score 5 , it was highest $2.00 \pm 2.82$. There was statistical no significant difference in the distribution of mean number of decayed surface according to grade of TFI.

Figure 6 shows that TFI is having a positive weak but not significant correlation with a mean number of caries surface, incisor, and molar eruption. Positive correlation indicates that as TFI score is increasing, the mean number of caries surface, erupted molar, and incisor teeth were also increasing $(p>0.05)$.

\section{Discussion}

Dental fluorosis is a diffuse hypomineralization disorder of ameloblasts that occurs with exposure to fluoride in developing enamel. $^{2}$ 


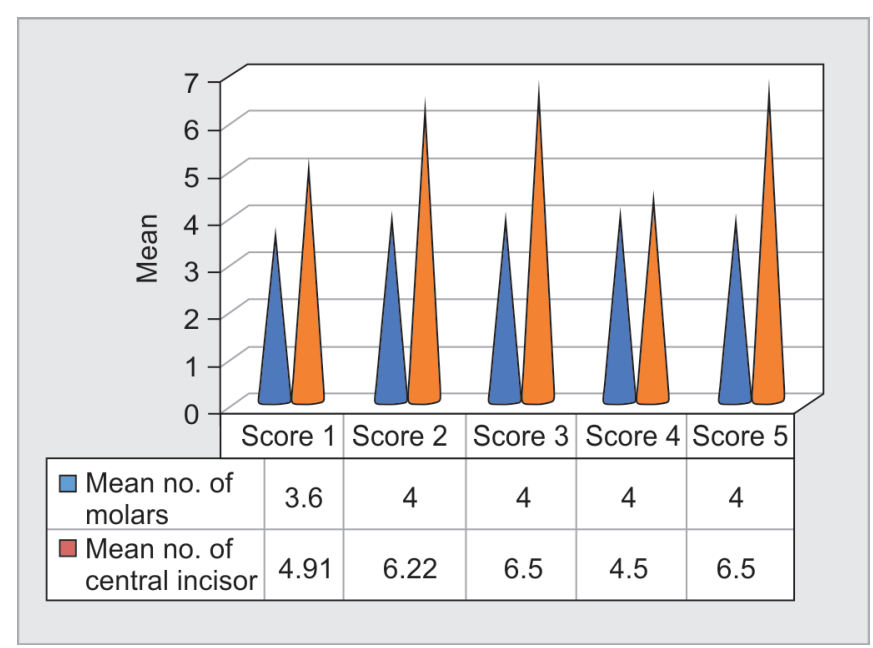

Fig. 2: Mean number of erupted incisor and molars according to grade of TFI among subjects with fluorosis

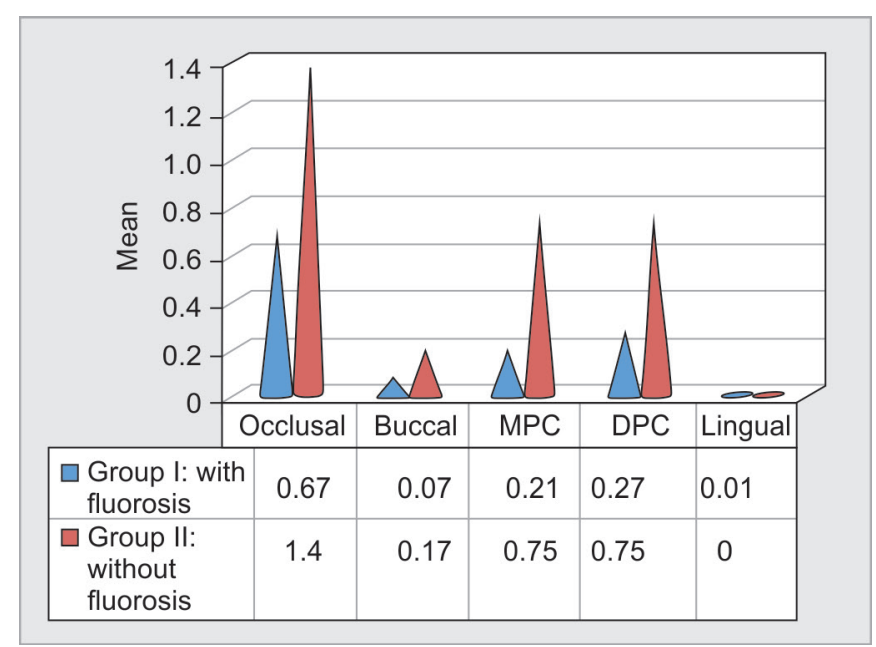

Fig. 4: Mean number of decayed tooth surface among subjects with or without fluorosis

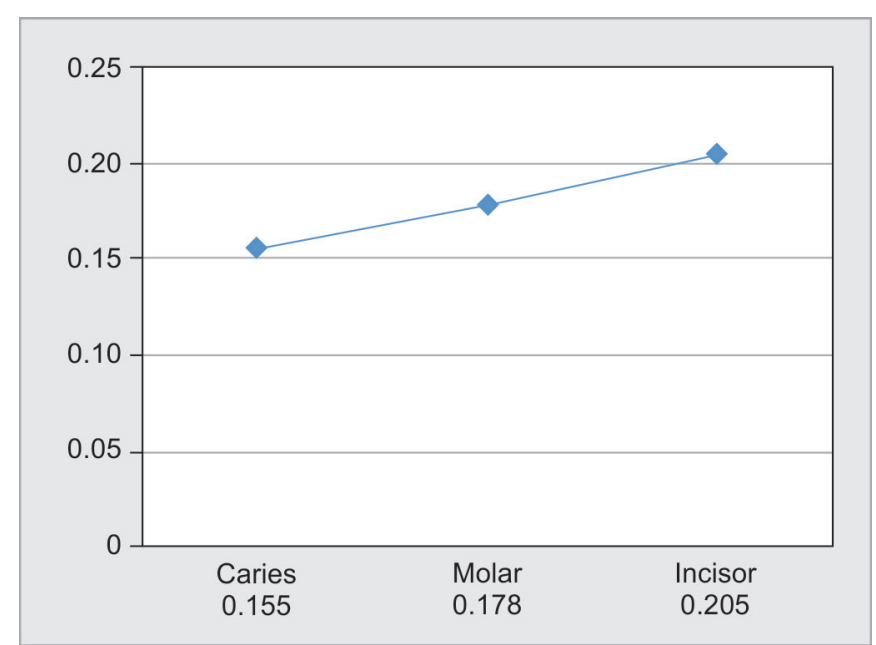

Fig. 6: Pearsons's correlation of Thylstrup and Fejerskov index for fluorosis (TFI) with a mean number of decayed surface, molar, and incisor teeth

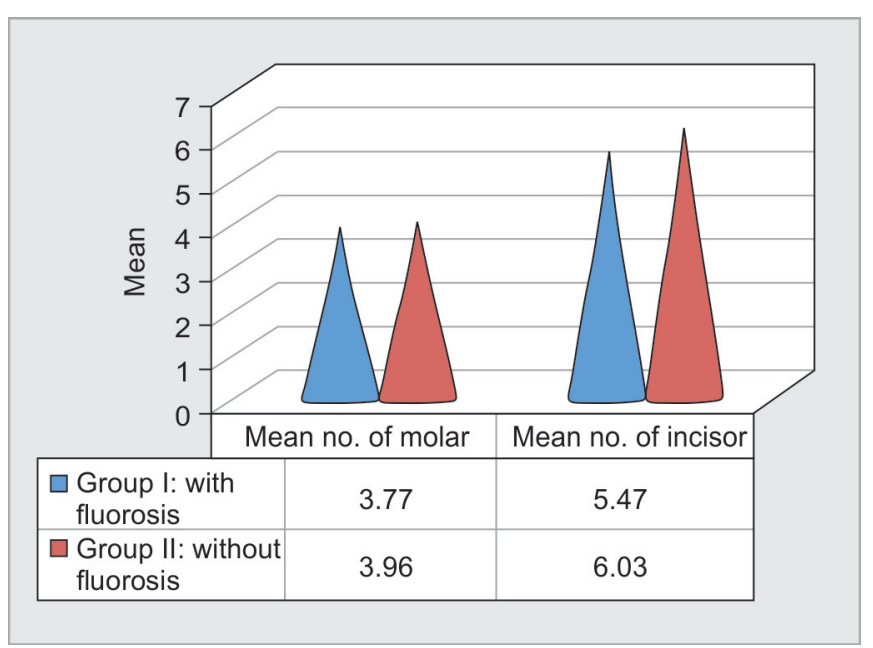

Fig. 3: Mean number of erupted incisor and molars among subjects with or without fluorosis

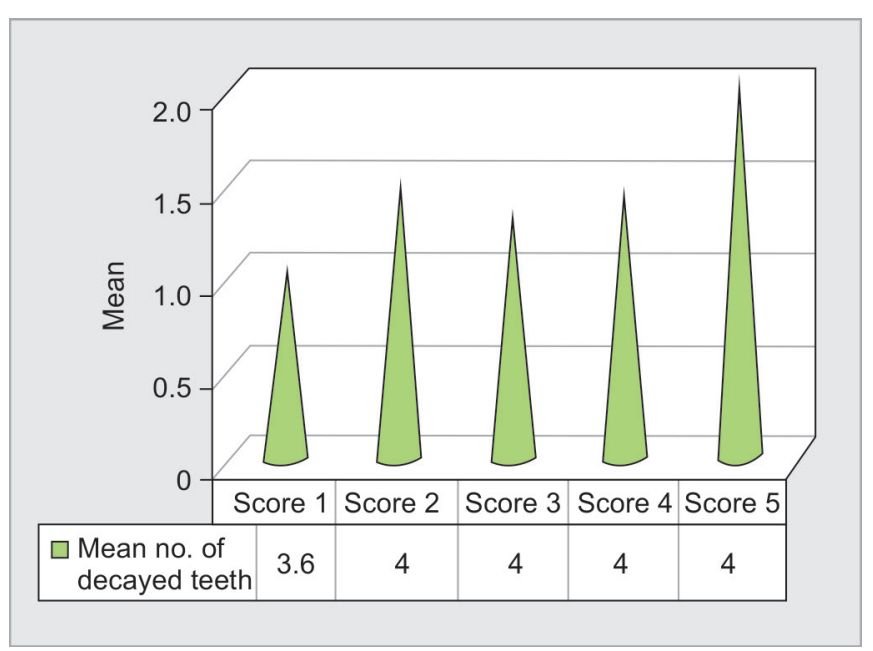

Fig. 5: Mean number of decayed tooth surface according to grade of TFI among subjects with fluorosis

\section{Dental Enamel: Structure and Chemistry}

Enamel consists of approx. 95\% of hydroxyapatite crystals, arranged in bundles of enamel prisms extending from dentin to the enamel surface. Crystals can incorporate extraneous ions from the surrounding environment, which substitutes for calcium, phosphate, and hydroxyl groups (Fig. 7). Fluoride can replace the hydroxyl ion. However, because of its high electronegativity and symmetrical charge distribution, instead of destabilizing the crystal, this results in a more stable crystal ${ }^{2}$ (Figs 8 to 10).

At low concentrations $(<1.0 \mathrm{mg} / \mathrm{L})$, drinking water fluoride has positive effects on teeth such as anticaries effect. However, too much fluoride (higher than $1.5-2 \mathrm{mg} / \mathrm{L}$ ) ingested for longer durations can cause dental fluorosis. ${ }^{3}$

Ameloblasts are very sensitive to fluoride during tooth development (Table 1). The low concentration fluoride (2 ppm) affects the appearance of the tooth. At high concentration, the tooth surface shows hypoplastic corrugations, as the tooth structure got altered. These changes are produced by ingestion of excessive fluoride during the period of tooth formation and calcification (during the first eight years of life). 


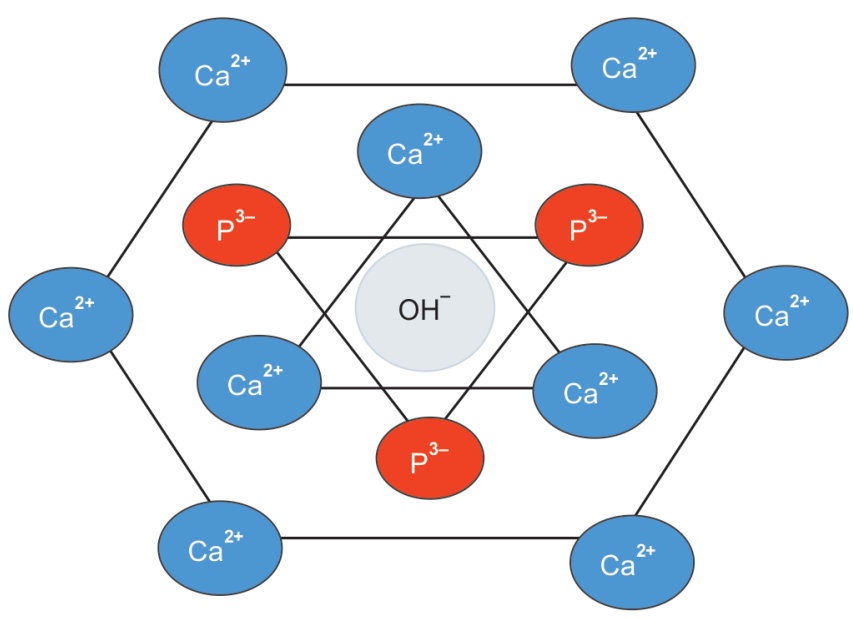

Fig. 7: Unit cell of hydroxyapatite showing central hydroxyl ion surrounded by triangles of calcium and phosphate, the whole surrounded by a hexagon of calcium ions

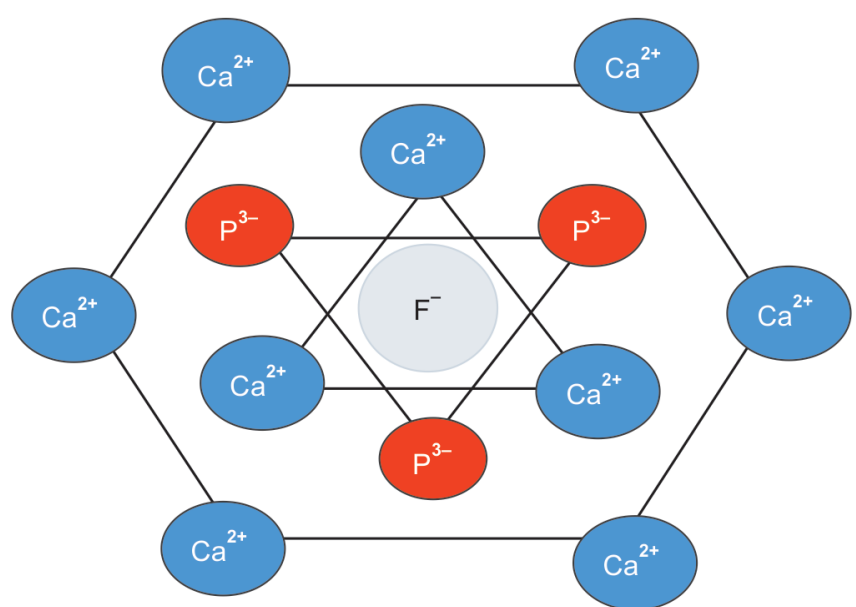

Fig. 8: Unit cell of hydroxyapatite showing central hydroxyl ion replaced by fluoride ion

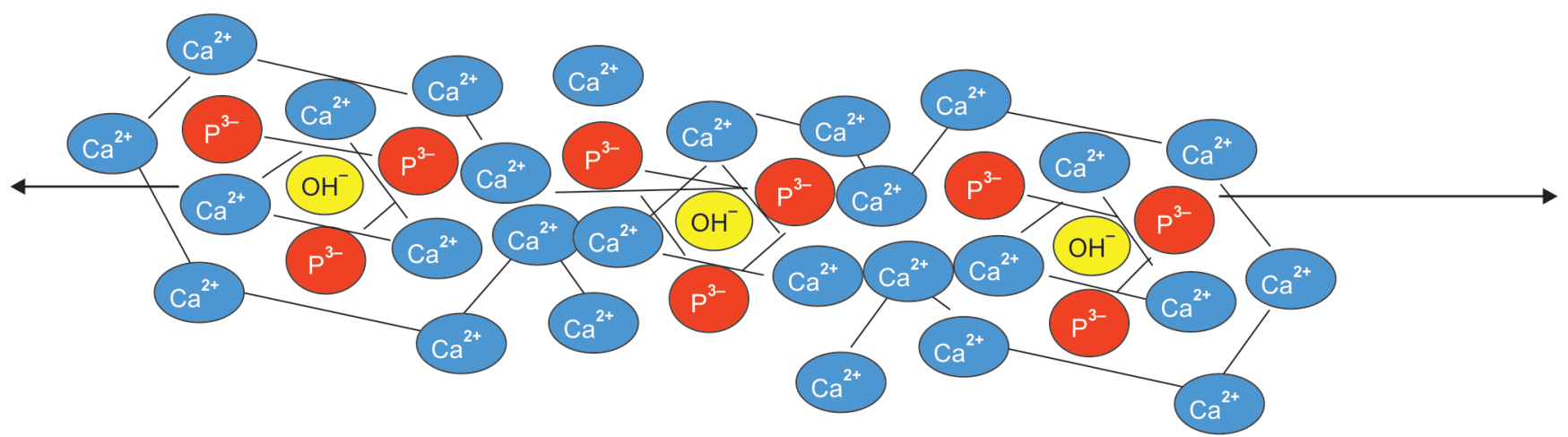

Fig. 9: Hydroxyapatite crystal showing the location of hydroxyl column with hydrogen bonding between hydroxyl ions

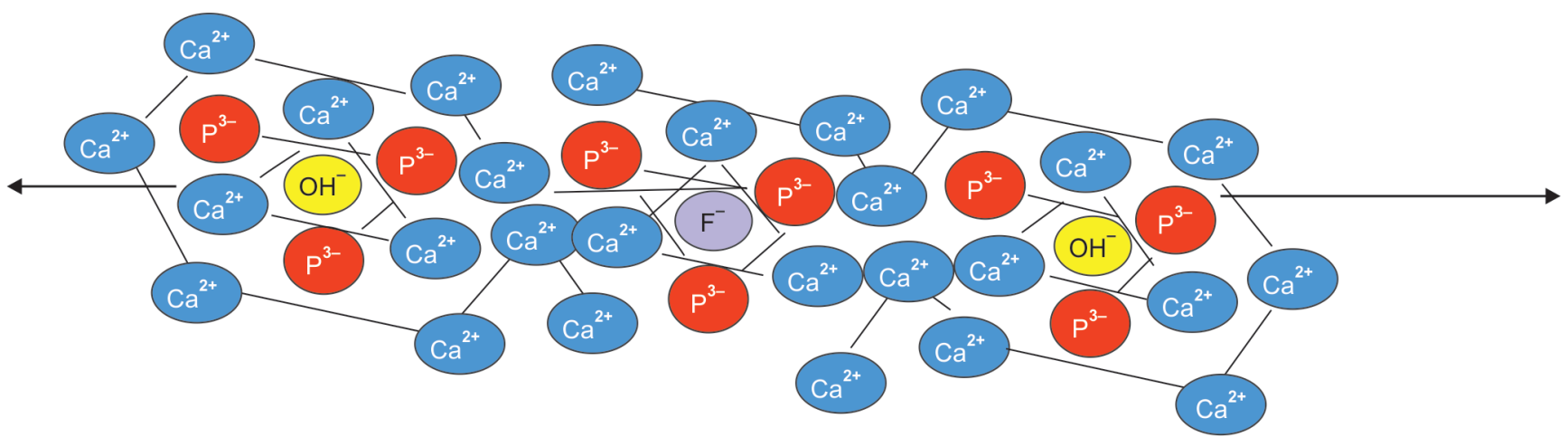

Fig. 10: Hydroxyapatite crystal showing replacement of one hydroxyl by a fluoride ion. The sense of the hydroxyl ions has changed with strong hydrogen bonds between fluoride and hydroxyl hydrogen atoms

Table 1: Showing clinical features of Fluorosis and pathogenic pathway followed by fluoride

\begin{tabular}{ll}
\hline Clinical features of dental fluorosis & $\begin{array}{l}\text { Pathogenic pathways followed by fluoride, affects the enamel } \\
\text { formation (Fejerskov et al.) }\end{array}$ \\
\hline $\begin{array}{l}\text { Teeth with dental fluorosis can resemble chalky white color owing to } \\
\text { reduced light refractivity because enamel prisms become defective }\end{array}$ & Effect on ameloblasts \\
$\begin{array}{l}\text { Feature of dental fluorosis are: Cloudy striated enamel, snow- capping, } \\
\text { yellowish-brown spots/brown pits seen on teeth }\end{array}$ & $\begin{array}{l}\text { Effect on nucleation and crystal growth in all stages of enamel } \\
\text { formation } \\
\text { In the severe form, fluorosed enamel is brittle and prone to fracture }\end{array}$ \\
$\begin{array}{l}\text { Effect on calcium homeostasis generally with dental fluorosis as } \\
\text { an indirect result }\end{array}$
\end{tabular}




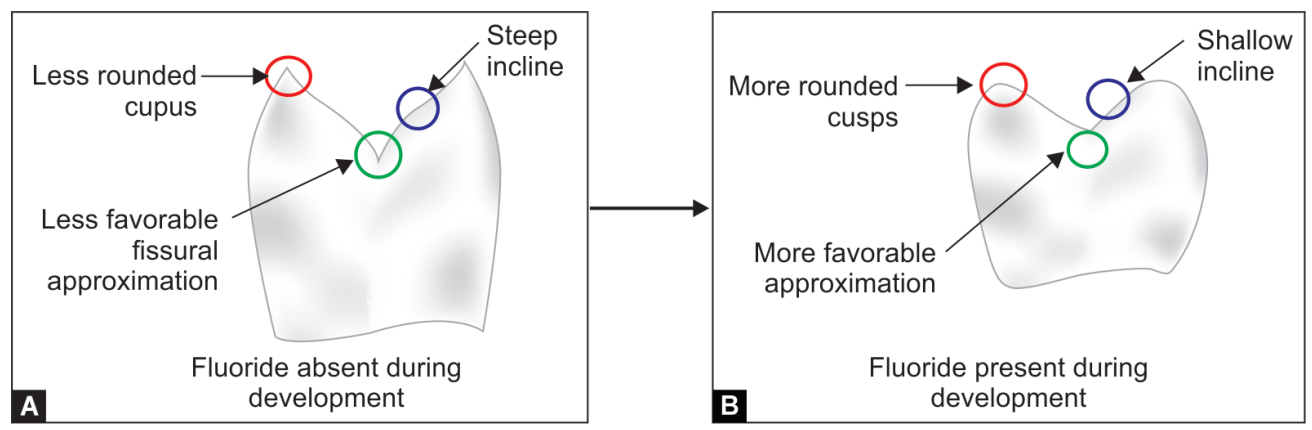

Figs $11 \mathrm{~A}$ and B: (A) Proposed morphology of molars formed in the absence of fluoridated water; (B) Proposed morphology of molars formed in the presence of fluoridated water

Fluorosis mainly affects the permanent dentition and at a very high concentration of fluoride ( $>10 \mathrm{ppm})$ in drinking water, can cross the placental barrier and affect primary dentition also. ${ }^{2}$

The finding of present study could not demonstrate the effect of fluorosis on timing of emergence of permanent teeth. Day, and Carlos et al. concluded that high fluoride concentrations in the drinking water provide more caries protection. ${ }^{4,5}$

Ainsworth concluded that children living in area with high fluoride concentrations in the drinking water experienced delayed emergence of permanent teeth. ${ }^{19}$ Moller found that higher fluoride concentration result in lower caries prevalence in deciduous teeth and teeth would retain until the time of physiological shedding. ${ }^{4,6,7}$

Findings of this study consistent with some other studies stating that increase fluoride concentration reduces the caries attack rate suggesting the fluoride has a cariostatic effect by:

\section{- Effect on tooth morphology}

Proponents of the systemic benefits of fluoride therapies claim that the morphology of the molars is affected by fluoride to such an extent as to render the occlusal surfaces more resistant to bacterial invasion and demineralization (Fig. 11). ${ }^{8}$ The size and shape of a tooth is not preserved until mineralization of the hard tissues occurs.

According to Cooper and Ludwig, the differences in shape and size could be due to the physical properties of fluorapatite.

The differences in the dimensions of the teeth observed align more closely with a model for tooth morphogenesis proposed by Osborn, where physical forces are considered to be the determinant of crown form, rather than genes, as proposed in gene-based models (Jernvall et al., Salazar-Ciudad and Jernvall). ${ }^{9}$

According to Osborn, there exists an imbalance between an action component of force (acting on, or in, the inner enamel epithelium) and resistance offered by the proteoglycan-rich stellate reticulum. ${ }^{10}$

According to Groeneveld, in surfaces with high caries susceptibility, e.g., pits and fissures, the greater part of the reduction is derived from pre-eruptive fluoride, while in surfaces with a low susceptibility, i.e., smooth surfaces, post-eruptive fluoride is more significant. ${ }^{11}$

- Effect on reducing solubility of tooth mineral by formation of more acid resistant apatite. ${ }^{12}$

- May bind to enamel proteins and increases their affinity for calcium. ${ }^{13}$

Proximal caries are less due to stagnation of fluoride into the proximal areas, which is not removed in later stages. ${ }^{14}$

Some investigations demonstrate the relationship between trace amounts of fluoride in community water supplies, the prevalence of mottled enamel, and a reduction in dental caries experience. The range of fluoride concentration most effective in preventing dental caries was established at approximately 1.0-1.5 ppm, well below the critical point in the causation of mottled enamel. Because of several climatological influences (extremely high temperature and humidity), children drink more water than children living in more temperate climates. As a result, there is increased ingestion of fluoride in relation to the concentration found in the water supply, which is a major factor contributing to the increased severity of endemic fluorosis. ${ }^{15} \mathrm{From}$ infancy these children have consumed a lot of locally grown tea, which is a rich source of fluoride. High sweat loss and high water intake resulted in high serum $\mathrm{F}$ levels, which also contributed to dental fluorosis. ${ }^{16} \mathrm{Few}$ authors stated that concentrations higher than optimal levels of fluoride in the drinking water provide more caries protection. 3,17,18

If the concentration of fluoride is too high, additional caries protection may get diminished. Few authors found decline in caries with increases in water fluoride levels between 0 and $0.7 \mathrm{ppm}$, with little additional decline between 0.7 and $1.2 \mathrm{ppm}$ and at 0.7 , there was a suitable tradeoff between caries and fluorosis. ${ }^{17,19}$

According to Williams, severely fluorosed enamel has large and irregular spaces between enamel prisms so that bacteria and acid can quickly diffuse into these spaces. ${ }^{20}$

\section{LiMITATION}

Fluorosis develops in an individual during early infancy, at the time of calcification of teeth. The fluoride content of the water that was consumed during that period is of critical importance, but cannot be measured now. Only school children were selected for the present study because most of them could be available for investigation during working hours; so school drop-outs were excluded from our sample.

\section{Conclusion}

Dental fluorosis does not prevent caries however it controls the rate of its progression. According to this study, there exists a significant positive correlation in prevalence of caries and fluorosis, even though occlusal and proximal caries are less pronounced in fluorosis patients. Irregularities in tooth surface due to severe dental fluorosis can act as a game changer in caries progression. However, the severity of fluorosis was not related with caries occurrence. Fluorosis has no significant effect on eruption rates of permanent incisors and molars. Effect of fluoride in caries prevention can be altered by many factors such as climate, temperature, $\mathrm{pH}$, consumed foods, availability, and solubility of fluoride minerals. 


\section{Clinical Significance}

This study significantly help us to find out the relationship between fluoride and caries occurrence and suggests that fluorosis does not have a significant effect on the process of teeth eruption.

\section{References}

1. Dhar V, Bhatnagar M. Physiology and toxicity of fluoride. Indian J Dent Res 2009;20(3):350-355. DOI: 10.4103/0970-9290.57379.

2. Robinson C. Fluoride and the caries lesion: interactions and mechanism of action. Eur Arch Paediatr Dent 2009;10(3):136-140. DOI: 10.1007/BF03262674.

3. Ramezani $\mathrm{G}$, Valaie $\mathrm{N}$, et al. The effect of water fluoride concentration on dental caries and fluorosis in five Iran provinces: A multi-center two-phase study. Dent Res J 2015;12(1):31-37. DOI: 10.4103/17353327.150310 .

4. Leroy $R$, Bogaerts $K$, et al. The effect of fluorides and caries in primary teeth on permanent tooth emergence. Community Dent Oral Epidemiol 2003;31:463-470. DOI: 10.1046/j.1600-0528.2003. 00116.x.

5. Berkovitz BK. Effect of Fluoride on Eruption Rates of Rat Incisors. J Dent Res 1974;53(2):334-337. DOI: 10.1177/00220345740530022501.

6. Virtanen Jl, Bloigu RS, et al. Timing of eruption of permanent teeth: standard Finnish patient documents. Community Dent Oral Epidemiol 1994;22:286-288. DOI: 10.1111/j.1600-0528.1994. tb02052.x.

7. Krumholt $\mathrm{L}$, Roed-Ptersen $\mathrm{B}$, et al. Eruption times of the permanent teeth in 622 ugandian children. Archs Oral Biol 1971;16:1281-1288. DOI: 10.1016/0003-9969(71)90031-8.

8. Limeback H. A re-examination of the pre-eruptive and posteruptive mechanism of the anti-caries effects of fluoride: is there any anti-caries benefit from swallowing fluoride? Community Dent Oral Epidemiol 1999;27:62-71. DOI: 10.1111/j.1600-0528.1999. tb01993.x.
9. Cooper VK, Ludwig TG. Effect of fluoride and of soil trace elements on the morphology of the permanent molars in man. N Z Dent J 1965;61:33-40.

10. Osborn WJ. A model of growth restraints to explain the development and evolution of tooth shapes in mammals. J Theor Biol 2008;255: 338-343. DOI: 10.1016/j.jtbi.2008.09.008.

11. Groeneveld A, Van Eck AA, et al. Fluoride in Caries Prevention: Is the Effect Pre- or Post-eruptive? J Dent Res 1990;69:751-755. DOI: $10.1177 / 00220345900690 S 145$.

12. LeGeros RZ, Glenn FB, et al. Some Physico-chemical Properties of Deciduous Enamel of Children With and Without Pre-natal Fluoride Supplementation (PNF). J Dent Res 1985;64(3):465-469. DOI: $10.1177 / 00220345850640031601$.

13. Simmer JP, Fincham AG. Molecular mechanisms of dental enamel formation. Crit Rev Oral Biol Med 1995;6(2):84-108. DOI: 10.1177/10454411950060020701.

14. Lynch RJ. The primary and mixed dentition, post-eruptive enamel maturation and dental caries: a review. Int Dent J 2013;63(Suppl. 2): 3-13. DOI: 10.1111/idj.12076.

15. Galagan JD, Lamson GG. Climate and Endemic Dental Fluorosis. Public Health Rep 1953;68(5):497-508. DOI: 10.2307/4588461.

16. Warnakulasuriya KA, Balasuriya $S$, et al. Determining optimal levels of fluoride in drinking water for hot, dry climates-a case study in Sri Lanka. Community Dent Oral Epidemiol 1992;20:364-367. DOI: 10.1111/j.1600-0528.1992.tb00700.x.

17. Ermis RB, Koray F, et al. Dental caries and fluorosis in low- and highfluoride areas in Turkey. Quintessence Int 2003;34(5):354-360.

18. Narbutaite J, Vehkalahti MM, et al. Dental fluorosis and dental caries among 12-yr-old children from high and low-fluoride areas in Lithuania. Eur J Oral Sci 2007;115:137-142. DOI: 10.1111/j.16000722.2007.00434.x.

19. Russell AL. Dental effects of exposure to fluoride-bearing dakota sandstone waters at various ages and for various lengths of time. 1948;28(3):298-309.

20. Forsman B. Dental fluorosis and caries in high-fluoride districts in Sweden. Community Dent Oral Epidemiol 1974;2:132-148. DOI: 10.1111/j.1600-0528.1974.tb01671.x. 